\title{
Rational water use in the US: the potential for the retrofit of simple residential technologies
}

\author{
S. Mecca, W. Brown, A. Callahan \& P. Mulligan \\ Department of Engineering-Physics-Systems, Providence College, USA
}

\begin{abstract}
Water withdrawals for residential use in the US exceeded 14.8 trillion gallons in 2000. There is ample evidence that, at least in certain regions, current water demand is not sustainable. What is the potential for reduced residential demand in the United States? This paper examines this question by developing and applying a rational use scenario in which present consumption is examined against water conservation opportunities that would make economic sense to users. Optimal technologies applied to present patterns of use by residential household type are analyzed and the total water avoidance is presented as a function of effective consumer discount rate and cut-off cost effectiveness ratio. Results indicate a potential avoidance of approximately 3 trillion gallons per year.
\end{abstract}

Keywords: residential US water demand, conservation, rational water use, sustainable water use.

\section{Introduction}

Residential water withdrawals in the United States exceeded 14.8 trillion gallons in 2000 [1]. While shortfalls in supply in the southwestern parts of the country have been reported for some time [2], the influence of factors such as global warming on the hydrological cycle during the past 50 years has affected the western states as well and across the United States one finds conflicts on water rights and economic stress resulting from both shortfalls of supply and changing rate structures. Much of the country's fresh water is used in agriculture and thermal energy production though end use by sector depends on municipality and region. This paper focuses on residential consumption, which is very much tied 
to family size and household type with only modest dependence on locale than what one finds in other sectors of demand.

The analysis considered various water conservation opportunities (WCOs) that involve modest capital costs. While behavioral changes, such as turning off the faucet when brushing teeth or taking shorter showers, are important, these were not considered in the analysis. The specific WCOs used in the model were faucet aerators, low flow showerheads, low flush toilets, efficient clothes washing machines, and efficient dish washing machines; the retrofit of cisterns and grey water systems, which are capital intensive investments, were not considered in this retrofit model. Urinal block technologies, such as the ecoDisc were not considered as the urinal is not a common fixture in residential households. Data was assembled on various brands and models of the targeted devices and appliances, and generally the device with the greatest reduction in water use per dollar of initial cost was implemented in the model. These efficient devices were then considered for each of the household types representing the residential sector based on the number of occupants and the style of household. If the devices could be implemented in the household, they were included in the model.

Once each device was implemented in the appropriate household, the water savings for that technology was calculated. This water savings was primarily dependent on the number of occupants in a household and the savings per periodic use. The water savings were converted into utility cost avoidance using national average water rates. The present value of this savings over the lifetime of the individual technology using a particular discount rate was calculated and a cost effectiveness ratio, $\mathrm{CE}$, defined as this present value of savings divided by the initial cost was determined. If the $\mathrm{CE}$ did not reach a specific minimum value, the device was considered impractical in the model and was not used. In other words, if a device could not at least return a high enough CE, i.e. present value of utility savings in relation to the initial outlay, it was considered that the household would not purchase the device.

Once all of the appropriate devices were implemented, the total water savings was calculated by household. These savings were then aggregated for all households taken from 2006 Census data [3]. This national savings, as well as the household savings, was then tested using a range of discount rates and cost effectiveness ratios. Changing these parameters affects the returns a given household will see from a technology, and thus as the discount rate and cost effectiveness cutoff increased, technologies were no longer implemented and potential savings would all accordingly.

\section{Rate structure}

Water and sewer rate structures differ in both method and price differentials in the United States. One third of the country has a pricing structure which charges a rate linearly proportional to the volume consumed; $31 \%$ of the U.S. has a rate which increases with increasing consumption and $34 \%$ have a rate which decreases with increasing consumption [1]. Water and sewer rates have been 
rising on the order of $10 \%$ during the past decade with cost of service often running less than the price to consumers [4]. Typical average water rates are currently in the range of $\$ 3$ to $\$ 4$ per 1000 gallons and sewer rates $\$ 4$ to $\$ 5$ per 1000 gallons to the consumer, though combined rates of $\$ 17$ per 1000 gallons have been reported recently. The rates used in the model runs reported herein use $\$ 9$ per 1000 gallons for combined water and sewer utility charges and $\$ 0.10$ per $\mathrm{kWh}$ for energy charges.

\section{Household matrix development}

There have been extensive studies of residential water use and demand; certain ones have examined instantaneous consumption through the course of a day [5], some at the spectra of usage frequency [6], others at the influence of rates, property value, household size and meteorological factors [7] and still others looking at national aggregate per capita consumption against aggregate withdrawals over long periods of time [8]. The American Water Works Association (AWWA) Residential End Uses of Water Study (REUWS) [9] used 22 water providers to monitor specific end-uses of water including toilets, showers, clothes washers, dishwashers, faucets and other uses in some 1188 single family households across the United States. These data were used in an earlier study in our laboratory to normalize residential demand to water consumption [10]. While spatial and temporal distributions were not used in the present study, household type and occupancies were broken out to establish water consumption by fixture/appliance for each household type using baseline consumption that took into account the data in the aforementioned AWWA study.

Twenty-one distinct households (HH ID) were considered based on occupancy (1 to 7 ) combined with household type: single family (HHT=1), apartment $(\mathrm{HHT}=2)$ and mobile home or trailer $(\mathrm{HHT}=3)$. These are shown in table 1.

So, for example, household number $5(\mathrm{HH}$ ID $=5)$ is a 2 person apartment. While discount rates, I, will certainly vary by income, which also interplays with household type, the factor was considered as an overall parameter to be varied in the model rather than breaking out discount rate values by $\mathrm{HH}$ ID. The aforementioned constraints of certain WCOs were also taken into account, so, for example a cistern would not be considered for a mobile home in the model.

Another assumption made in the model is the independence between household income and the implementation of a WCO. If a certain WCO yields a cost effectiveness ratio greater than or equal to one, the technology is implemented, regardless of the initial cost. Although this may seem naïve, the implementation of an efficient technology in households or organizations with insufficient capital could occur through a quasi utility.

Finally, 2006 US Census Bureau data [3] was used to quantify the number of US households in each the 21 types noted in table 1 . This distribution is given in Figure 1. 
Table 1: $\quad$ Household identification. See text.

\begin{tabular}{ccc}
\hline HH ID number & \# of occupants & HH type \\
1 & 1 & 1 \\
2 & 1 & 2 \\
3 & 1 & 3 \\
4 & 2 & 1 \\
5 & 2 & 2 \\
6 & 2 & 3 \\
7 & 3 & 1 \\
8 & 3 & 2 \\
9 & 3 & 3 \\
10 & 4 & 1 \\
11 & 4 & 2 \\
12 & 4 & 3 \\
13 & 5 & 1 \\
14 & 5 & 2 \\
15 & 5 & 3 \\
16 & 6 & 1 \\
17 & 6 & 2 \\
18 & 6 & 3 \\
19 & 7 & 1 \\
20 & 7 & 2 \\
21 & 7 & 3 \\
\hline
\end{tabular}

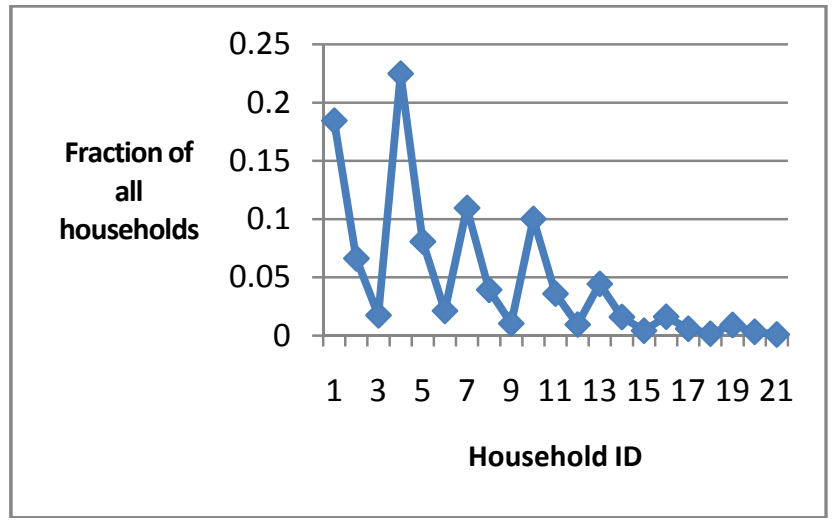

Figure 1: Distribution of households by ID. See Table 1.

\section{WCO assumptions}

All consumers in this model were assumed to act rationally when presented with a WCO. By rational, we mean a consistent consideration of benefits and costs. A simple criterion was developed, what we call the $\mathrm{CE}$ ratio defined as the initial cost over the present value of utility savings. If a WCO had a $\mathrm{CE}$ ratio greater than or equal to one, the device was implemented. The device was implemented for the utility savings, not to replace an old water technology. The difference is subtle, but important. For example, if a consumer in the model was assumed to 
own a dishwasher in need of replacing, there would be a dramatic reduction in the initial cost. The family would need to purchase a replacement dishwasher, water efficient or otherwise. The lower of these two costs was considered a sunk cost, which would be spent on $a$ dishwasher. This leads to the another important assumption, i.e. that all technologies in the home are not already water efficient. Though this is certainly not the case, the assumption was used in the initial calculations then adjusted later in the model. For example, it was assumed initially that all current toilets did not have the efficiency of a low flush toilet. To find the actual efficiency of current toilets, a weighted average of low flush toilets and high flush toilets was found. This average flush was then reduced by an appropriate percentage by low flush toilets, and applied to all households. In reality, certain households would already have a low flush toilet, and would not need to make this investment again. Therefore, with this particular model, the water savings by household, or for the nation, is somewhat overstated. The actual water savings will be somewhat less, because some households are already operating at a conservative level.

Our model also assumed that quality would not be a factor in a new WCO. Consumers would purchase a technology because of its financial benefit, and not for its aesthetic appeal or for its inherent technology. Similarly, the number of uses was assumed to remain constant with the implementation of a new device. This means, for example, that the frequency and duration of showers taken before the implementation of a WCO would be the same as those taken after the implementation of the WCO.

Finally, the maintenance costs of a WCO were assumed to be no greater than nor less than their inefficient counterpart, unless there was a particular maintenance difference specified by the manufacturer. For example, a low flow showerhead would need no more maintenance than a high flow showerhead, whatever that maintenance might be.

\section{WCO analyses}

Specific appliance- and device-based WCOs were selected generally based on a minimization of the percent reduction in water per dollar initial cost. Such investments are enhanced by energy savings as well as water savings. The selections of devices and appliances are summarized as follows:

\subsection{Aerators}

Faucet aerators are easily installed and are a relatively inexpensive way to lower a household's water dependence. Their main function is to decrease the flow of water from the faucet so less water is wasted when the sink is used. The more expensive aerators will use air pressure to simulate a higher flow than is actually being experienced. Nine aerator models of varying cost and flow rate were compared relative to a standard average flow rate of 2.5 gallons per minute. (Note that there are households with aerator flow rates of 3.5 gallons per 
minute!) The results are shown in table 2. The selected aerator with a cost of $\$ 3.25$ and a flow rate of $0.5 \mathrm{gal} / \mathrm{min}$ is noted.

Clearly, with such modest initial cost and return faucet aerators will prove to be a wise investment for a wide range of discount rates and for all household types.

Table 2: $\quad$ Analysis of nine faucet aerators.

\begin{tabular}{|c|c|c|c|c|}
\hline & & Standard & & Percent \\
\hline Cost (\$) & $\begin{array}{l}\text { Flow Rate } \\
\text { (gal/min) }\end{array}$ & $\begin{array}{l}\text { Flow Rate } \\
\text { (gal/min) }\end{array}$ & $\begin{array}{l}\text { Percent } \\
\text { Reduction }\end{array}$ & $\begin{array}{l}\text { Reduction per } \\
\text { dollar }\end{array}$ \\
\hline$\$ 7.50$ & 2 & 2.5 & $20.00 \%$ & 2.67 \\
\hline$\$ 5.99$ & 2.2 & 2.5 & $12.00 \%$ & 2.00 \\
\hline$\$ 1.75$ & 2.2 & 2.5 & $12.00 \%$ & 6.86 \\
\hline$\$ 4.00$ & 2.2 & 2.5 & $12.00 \%$ & 3.00 \\
\hline$\$ 4.25$ & 1.5 & 2.5 & $40.00 \%$ & 9.41 \\
\hline$\$ 3.25$ & 2.2 & 2.5 & $12.00 \%$ & 3.69 \\
\hline$\$ 3.25$ & 2.2 & 2.5 & $12.00 \%$ & 3.69 \\
\hline$\$ 3.25$ & 0.5 & 2.5 & $80.00 \%$ & 24.62 \\
\hline$\$ 1.50$ & 2.2 & 2.5 & $12.00 \%$ & 8.00 \\
\hline
\end{tabular}

\subsection{Showerheads}

Like aerators, efficient showerheads are inexpensive, easy to install, and, at least for the better quality models will simulate additional flow by using available air pressure. An analysis of different models' performance against the US standard from 1992, $2.5 \mathrm{gal} / \mathrm{min}$, is shown in Table 3. Again the selected showerhead with a \% water reduction per dollar of $2.96 \%$ /dollar is indicated with the arrow. As with the case with aerators, showerheads will prove to be a wise investment over a wide range of discount rates.

Table 3: $\quad$ Analysis of eight showerheads.

\begin{tabular}{|c|c|c|c|c|}
\hline & & Standard & & Percent \\
\hline Cost & $\begin{array}{l}\text { Flow } \\
\text { Rate(gal/min) }\end{array}$ & $\begin{array}{l}\text { Flow Rate } \\
\text { (gal/min) }\end{array}$ & $\begin{array}{l}\text { Percent } \\
\text { Reduction }\end{array}$ & $\begin{array}{l}\text { Reduction } \\
\text { Per Dollar }\end{array}$ \\
\hline$\$ 13.55$ & 2 & 2.5 & $20.00 \%$ & 1.48 \\
\hline$\$ 113.00$ & 1.98 & 2.5 & $20.80 \%$ & 0.18 \\
\hline$\$ 16.00$ & 1.75 & 2.5 & $30.00 \%$ & 1.88 \\
\hline$\$ 31.99$ & 1.8 & 2.5 & $28.00 \%$ & 0.88 \\
\hline$\$ 15.00$ & 2 & 2.5 & $20.00 \%$ & 1.33 \\
\hline$\$ 45.00$ & 1 & 2.5 & $60.00 \%$ & 1.33 \\
\hline$\$ 27.00$ & 0.5 & 2.5 & $80.00 \%$ & 2.96 \\
\hline$\$ 99.00$ & 1.9 & 2.5 & $24.00 \%$ & 0.24 \\
\hline
\end{tabular}

\subsection{Toilets}

Most of the efficient toilets analyzed in this study use a dual flush system. Although they are common in Europe, dual flush toilets have yet to make a 
serious impact in the US. Efficient, single flush toilets simply use less water per flush than a standard toilet.

For this study, eight toilets were compared by their average flush rate (that is a weighted average between both flushes of the duel flush system is the toilet is a dual flush) to an average flush rate of 3.1 gallons per flush. This is a conservative estimate based on: 1 . an historical US toilet standards profile: Pre19507.0 gallons per flush (gpf); 1950-1980 5.0 gpf; 1980-1994 3.5-4.5 gpf; Post-1994 1.6 gpf, 2. The aforementioned AWWA study [9] and 3. Energy Star ratings [11]. The results of the analysis are shown in table 3 .

The model will indicate that, for all discount rates from 1 to $20 \%$, efficient toilets are never a prudent investment for any single person household. As discount rates reach $8 \%$ and above, it becomes apparent that, even in larger family households, efficient toilets are not a rational investment.

Table 4: Analysis of eight toilets.

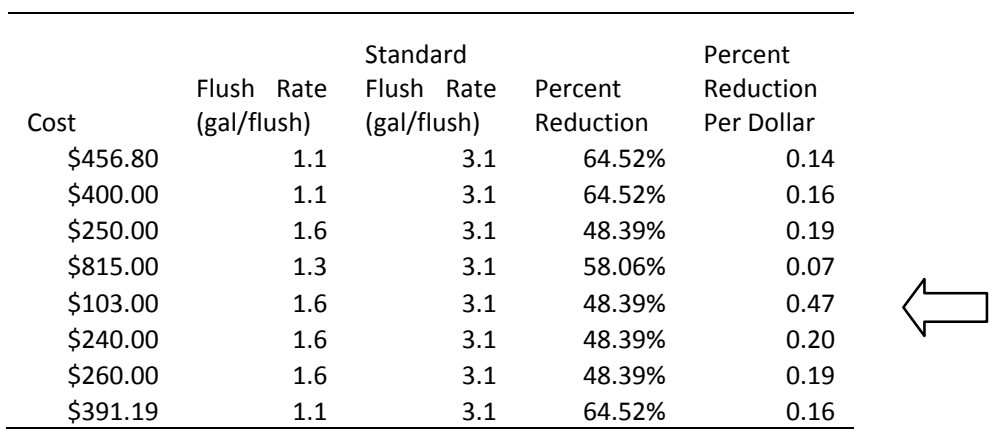

\subsection{Clothes washers and dishwashers}

Clothes and Dishwasher analyses are given in tables 5 and 6 .

Both water and energy savings were considered in the model for the selected clothes and dishwashers.

Table 5: $\quad$ Analysis of eight clothes washers.

\begin{tabular}{cccrll}
\hline Cost (\$) & $\begin{array}{l}\text { Water Use } \\
\text { (gal/yr) }\end{array}$ & $\begin{array}{l}\text { Baseline } \\
\text { Water Use } \\
\text { (gal/yr) }\end{array}$ & $\begin{array}{l}\text { Percent } \\
\text { Reduction }\end{array}$ & $\begin{array}{l}\text { Percent } \\
\text { Reduction per } \\
\text { Dollar }\end{array}$ \\
999 & 4692 & 14331 & $67.26 \%$ & 0.067 \\
589 & 8455 & 14331 & $41.00 \%$ & 0.070 \\
739 & 5272 & 14331 & $63.21 \%$ & 0.086 \\
839 & 4948 & 14331 & $65.47 \%$ & 0.078 \\
619 & 8185 & 14331 & $42.89 \%$ & 0.069 \\
1499 & 5455 & 14331 & $61.94 \%$ & 0.041 & $0.092 \quad$ \\
669 & 5521 & 14331 & $61.48 \%$ & 0.067 \\
1229 & 2612 & 14331 & $81.77 \%$ &
\end{tabular}


Table 6: Analysis of eleven dishwashers.

\begin{tabular}{rrrrr}
\hline Cost (\$) & \multicolumn{1}{l}{$\begin{array}{l}\text { Water } \\
\text { Use (gal/ } \\
\text { load) }\end{array}$} & $\begin{array}{l}\text { Baseline } \\
\text { Water } \\
\text { Use (gal/ } \\
\text { load) }\end{array}$ & $\begin{array}{l}\text { Percent } \\
\text { Reduction }\end{array}$ & $\begin{array}{l}\text { Percent } \\
\text { Reduction per } \\
\text { Dollar }\end{array}$ \\
$\$ 1,403.03$ & 2.64 & 6 & $56.00 \%$ & 0.040 \\
$\$ 2,023.45$ & 2.64 & 6 & $56.00 \%$ & 0.028 \\
$\$ 466.26$ & 3.432 & 6 & $42.80 \%$ & 0.092 \\
$\$ 689.33$ & 3.432 & 6 & $42.80 \%$ & 0.062 \\
$\$ 543.37$ & 3.168 & 6 & $47.20 \%$ & 0.087 \\
$\$ 624.47$ & 3.168 & 6 & $47.20 \%$ & 0.076 \\
$\$ 504.85$ & 3.168 & 6 & $47.20 \%$ & 0.093 \\
$\$ 713.88$ & 3.168 & 6 & $47.20 \%$ & 0.066 \\
$\$ 1,249.94$ & 3.96 & 6 & $34.00 \%$ & 0.027 \\
$\$ 841.41$ & 3.96 & 6 & $34.00 \%$ & 0.040 \\
$\$ 466.33$ & 3.96 & 6 & $34.00 \%$ & 0.073 \\
\hline
\end{tabular}

\subsection{Cisterns and grey water systems}

As noted earlier, this paper deals with relatively low cost retrofit technologies and, hence, capital intensive systems, such as cisterns and grey water systems, which can cost $\$ 10,000-\$ 20,000$ in retrofit situations [12, 13], were not considered. Yet cisterns, which have been modeled in our laboratory [14], can have dramatic impact on residential water withdrawals. Their potential is the subject of another study.

\section{Model results}

Water savings for all qualifying WCOs were calculated and aggregated over household ID, HHID, parametrically by discount rate and CE ratio. Qualifying WCOs are those having a net benefit greater than 0 , which here is equivalent to those having a CE ratio greater than 1 . Recall that the $\mathrm{CE}$ ratio is the ratio of the present value of benefits (water, sewer and energy savings) to the initial cost, i.e.

$$
C E=\frac{P V A F(i, n)(A W U S+A S U S+A E C S)}{I C} \geq 1,
$$

where

and

$$
\begin{aligned}
& A W U S=\text { annual water utility savings in } \$ \\
& A S U S=\text { annual sewer utility savings in } \$ \\
& \text { AEUS }=\text { annual energy utility savings in } \$
\end{aligned}
$$

$\operatorname{PVAF}(\mathrm{i}, n)=$ the present value of $1 \$$ received annually for $n$ years at a discount rate, $i$.

Model results will ultimately depend on a number of factors including the effective life of the WCOs though, as long as this exceeds the lifetime parameter, $n$ (in the present value factor, PVAF), one can consider the results conservative 
in this regard. The other factors affecting the model results have been discussed earlier and include, water- sewer- and energy- rates, the distribution of household types/occupancy and the effective discount rate, i. This rate reflects the opportunities for investment on the part of the consumer and will be higher for higher income households. Given the variability in this factor and the CE ratio, that can be considered a cutoff value for worthy WCO investment decisions, these two were treated as parameters in the model results shown in Figure 2. For a small discount rate and a CE ratio cutoff of 1, i.e. where the present value of water related utility savings would equal the initial cost, the water savings to the US would be some 3.3 trillion gallons annually, i.e. more than $20 \%$ of the present residential water withdrawals. If we demand a $\mathrm{CE}$ ratio of 5, i.e. present value of utility savings that are 5 times the initial cost and a $10 \%$ discount rate, there would be some 2.55 trillion gallons of water saved annually with water and sewer utility savings of some 23 billion dollars to residential consumers or approximately $\$ 210$ per household.

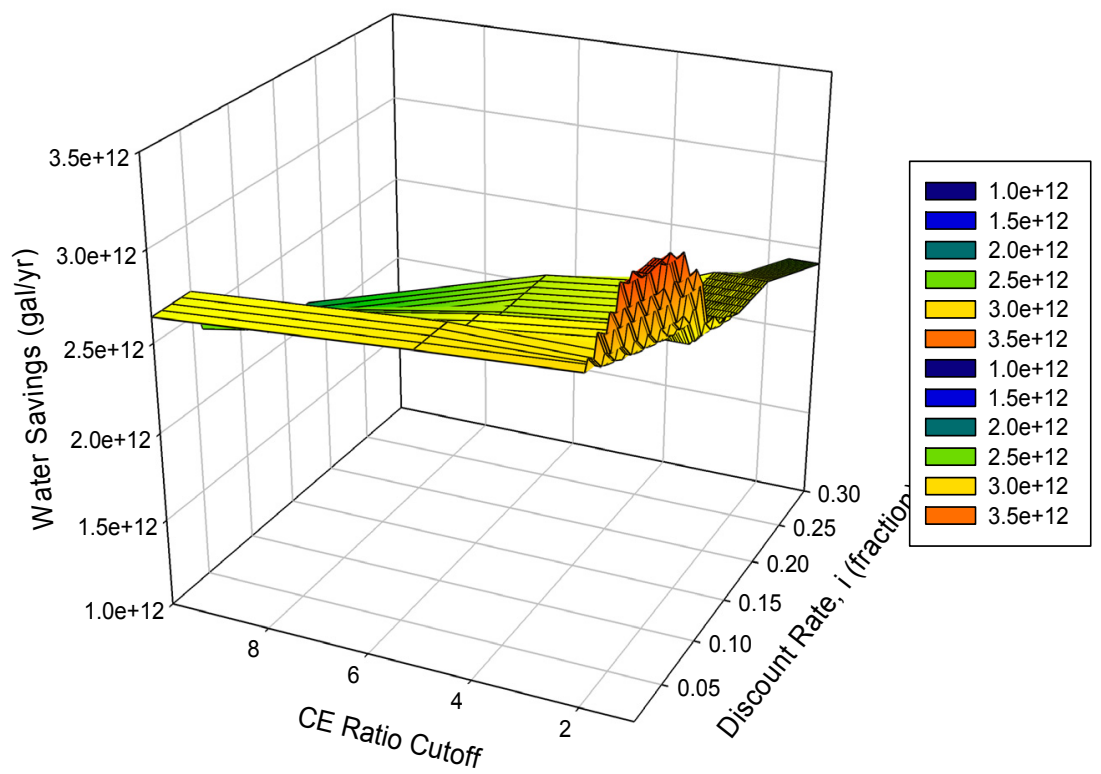

Figure 2: Annual water savings as a function of average consumer discount rate and $\mathrm{CE}$ ratio cutoff.

\section{Conclusions}

The potential water savings achievable through a rational choice of small retrofit investments in fixtures and appliances in the residential sector. Result of a parametric analysis of annual water savings by average consumer discount rate and cost-effectiveness ration, defined as the present value of utility savings over initial cost, shows that for reasonable values of these parameters, a potential 
water savings of some $20 \%$ with a consumer water-sewer utility avoidance of $\$ 210$ per household. WCOs considered in this analysis were limited to relatively low cost measures related to indoor water use, which is far less variable in the US than is outdoor use. The latter also offers opportunities for rational management decisions. As water withdrawals in the US continue to exceed replenishment, the simple technologies used in this paper will be augmented by more capital intensive strategies, such as grey water and recirculation systems and the use of rain water harvesting cisterns, which offer the potential for larger water savings though with correspondingly higher initial costs. Such systems are being studied in our laboratory and in many others around the world.

Finally this model only covers the residential water use in the United States. Water supply issues are a global problem and demand crosses many sectors. In the US thermal energy production and irrigation account for over $80 \%$ of water use; rational choice models are even more important in these sectors.

\section{Acknowledgements}

The authors thank Stephen D. Mecca, President of ecoWise Systems for his guidance throughout the course of this study.

\section{References}

[1] Gleick, Peter, The World's Water: The Biennial Report on Freshwater Resources, Island Press, Washington, 2002.

[2] USGS, Water Use in the United States, http://water.usgs.gov/watuse/, 2000.

[3] US Census Bureau, http://www.census.gov/.

[4] Raftelis Financial Consulting 2000 Water and Wastewater Rate Survey. Charlotte, N.C.: Raftelis Financial Consulting, PA, 2000.

[5] Guercio, R., Magini, R. \& Pallavicini, I., Temporal and spatial aggregation in modeling residential water demand, Water Resources Management II, edited by C.A. Brebbia, Progress in Water Resources Vol. 8, UK, 2000.

[6] Race, J., Burnell, D., Water Distribution Systems Analysis: Analysis of Domestic Water Patterns, Building Partnerships - 2000 Joint Conference on Water Resource Engineering and Water Resources Planning \& Management, section 50, chapter 4, 2000.

[7] Dandy, G.C., A Study of the Factors Which Affect Residential Water Consumption in Adelaide, Research Report No. R78, 1-56, 1987, Department of Civil Engineering, University of Adelaide.

[8] Perlman, H.A., Pierce, R.R., Solley, W.B., Estimated Use of Water in the United States in 1995, 1-27, 1998.

[9] American Water Works Association, Residential End Uses of Water. AWWA Research Foundation, 1999.

[10] Mecca, S. \& Dotto, S., Normalizing residential water demand to water consumption, Water Resources Management III, Ecology and the Environment, Vol. 80, edited by M. De Conceicao Cunha, University of 
Coimbra, Portugal and C.A. BREBBIA, Wessex Institute of Technology, UK, 2005.

[11] Consortium for Energy Efficiency, Energy Star Ratings, http://www.cee1.org/, 2007.

[12] http://www.texasmetalcisterns.net/Pages/pricing.html

[13] http://www.nutricyclesystems.com/price.htm

[14] Terentiuk, S., Letzring, \& D., Marios, P., Supplying fresh water to small island communities, Research Report, Department of Engineering-PhysicsSystems, Providence College, 2001. 